\title{
The Effect of Self-efficacy Improvement on the Effectiveness of Project Managers in Contemporary Organisations
}

\author{
Autram Jacobs*, Lebogang Kamohi \\ Pioneer Foods (PTY) Ltd. and Regenesys Business School, Pioneer Foods Enterprise Project Office, South Africa
}

Copyright $(2017$ by authors, all rights reserved. Authors agree that this article remains permanently open access under the terms of the Creative Commons Attribution License 4.0 International License

\begin{abstract}
Recent studies on the success rates of modern day projects have shown that the project management fraternity needs to go beyond merely achieving the current levels of excellence and become more relevant to the needs of the modern business environment. These modern, dynamic environments are characterised by high levels of pressure to perform, as well as rapid changes caused by advances in technology such as the internet. Factors such as globalisation and recessions are also playing a role in the increasingly intense cost-cutting contemporary organisation. Hence, the current project manager effectiveness factors previously researched like methodology, people-skills and leadership have brought project practice only so far and will not be all-encompassing in future. These refer to how the project manager relates externally during project practice, in terms of how the project manager relates to the project itself, the resources and stakeholders; but what of the project manager's own, internal self-assessment of his or her abilities in particular projects? How does the project manager handle him or herself, intrinsically and does this have an impact on the project manager's effectiveness in high-pressure contemporary business environments? If so, the awareness of this can create an improved project manager better equipped to handle him or herself in the new era. By means of meta-ethnography and qualitative research, it was found that a concept called self-efficacy is extremely relevant to project management in this regard, and enhances several personal attributes required for the project manager to thrive in these modern environments. The term 'self-efficacy' is defined as a person's own judgment of his or her capabilities to organise and execute the courses of action required to attain predetermined goals - hence the relevance to project managers. It is not concerned with the skills one has, but rather with the estimation of what one can attain with the skills one possesses. The researcher found that project managers who can manage their self-assessment with regards to their projects will be more effective in these turbulent times. The researcher's work also showed
\end{abstract}

self-efficacy having a significant improvement in 5 specific personal competencies sorely needed in contemporary organisations - Adaptability/flexibility, Ability to handle ambiguity, Persistence/perseverance, Emotional Intelligence and Resilience. Ultimately, the paper shows these 5 competencies being important in contemporary environments and that self-efficacy significantly improves or enhances these for project managers in modern companies. In so doing, the researcher gives a clear indication of the effect of self-efficacy improvement on the effectiveness of project managers in contemporary organisations.

Keywords Self-efficacy, Project Manager, Project Leadership, Contemporary Organisations

\section{Introduction}

Neuhauser (2007) alluded to the increased significance of project managers in the modern era by stating that they are now, more than ever, being relied upon as the people who are implementing corporate strategies and objectives rather than merely reporting status on a disaster. Muller (2009) stated that up to $30 \%$ of the world's economy is based on projects, and projects are the building blocks to the sustainable growth of businesses. Binde and Saulite (2013) stated that just 20\% of the success of a project depends on the approach to the actual management of the work involved in the project, while the remaining $80 \%$ depends on the role of the project manager and how successfully he or she performs. It is evident from these researchers that projects, and project managers, are playing a significant role in the success of organisations and the implementation of strategies. Hence it is vital to continually consider the evolution of the project manager and his or her competencies as a key factor in the success rate of these strategic organisational projects.

Recent research is showing that project managers in the 
contemporary era of fast-paced, dynamic business decision-making; require a whole new set of additional attributes over and above mere methodology improvements to thrive. Product life-cycles appear to be shorter and shorter; meaning the timelines for implementing strategic initiatives are shorter. Coetzee, Visagie and Ukpere (2012) stated that competitive pressures in markets have forced the rate of change and innovation to skyrocket, with the results often being turbulence in organisations. They claimed that economic conditions, labour markets, demographics, consumer preferences and technological changes are affecting how business is being conducted. More flexibility is required, which results in time-pressure and stress on project managers, as the cycle of business value of projects is shorter. Are modern project managers equipped with the awareness, understanding and skills, to deal with the challenges of the dynamic era of this new-age business environment?

According to Gul (2011:13571), "the recent re-examination of projects has consequently rendered the static and non-reactionary project environments of the Bodies of Knowledge less useful and immediately replaced it with a world that is both complex and dynamic". Arain and Tipu (2009:149) stated that "there is a need that business schools strive to improve the course offerings that incorporate the issues of complex, dynamic environments". This re-iterates that mere methodology or technical industry focus will not suffice. The intention of this research paper is to raise awareness of self-efficacy as an aspect of a project manager that could improve the intrinsic qualities needed.

The following literature review examines the evolution of project manager competencies through the years. It is a step through time leading to where the project manager skills focus areas are currently. It concludes with a suggestion on a new competency for the project fraternity to consider, called self-efficacy, to equip project managers for this dynamic and turbulent business environment. The literature review presents an explanation of self-efficacy, how to improve and maintain it, and the possible benefits to project managers.

\section{Literature Review}

\subsection{Project Management Effectiveness Factors Evolution}

The competencies needed by project managers have evolved significantly over the years, as can be seen in academic literature. In the early days of the profession, authors like Pinto and Kharbanda (1995) referred to "accidental project managers", stating that project managers of that era were often appointed due to their technical competency in industries like civil engineering, banking and IT. This appeared to be acceptable in that era.

Fisk (1997) then pointed out that project management was later found to be very similar to professional construction management. The need to see construction programmes completed timeously and within budget led to the classic notion that project manager effectiveness should be measured around the ability to manage projects within time, cost and quality constraints. Themistocleous and Wearne (2000) found that the emphasis at the turn of the century remained largely on factors like project planning, monitoring and control and risk analysis, as well as related classical project problems of execution. It is evident that during this period it was perceived that project managers abiding by project management life cycle and methodologies were a main determinant of effectiveness.

After the early 2000s the project management fraternity experienced a shift towards leadership focus, when the global trend moved towards separating the concepts of leadership and management. Project management has traditionally been a good fit with the planning, organising, leading and controlling aspects of the typical management framework, where management implements processes to drive a project towards successful completion. Leadership, however, is more concerned with motivating and helping people to realise their potential and achieve tough and challenging company goals. Accomplished project management researchers like Turner and Muller (2005) studied the link between project managers' effectiveness and their leadership competencies, finding that effective project managers need both management and leadership competencies. Neuhauser (2007) highlighted that one of the core elements of managing successful projects is the ability to manage project teams. He also stated that organisational effectiveness requires project managers to combine their technical competency of project methodology with an effective display of leadership. The work of Geoghegan and Dulewicz (2008) on the correlation between project managers' leadership competencies and project success further highlighted the conclusion that leadership has an impact on project manager effectiveness. Besides these major themes, other general attributes and competencies were also shown through the years, like political acumen for instance, to increase the effectiveness of project managers. Many of these are considered aspects of leadership.

Some recent studies though, have shown a much greater emphasis needed on more personal, intrinsic attributes of project managers. Meredith and Mantel (2010) explored project management capabilities such as being able to deal with failure and stress as being important, as project personnel of the current era often need to operate in turbulent and ever-changing environments. The work of Muller (2009) showed that project management involves much more than tools and techniques. He emphasised factors like matching projects to the psychological profile of the project manager, the importance of combining "emotional competence" with IQ and management intelligence and personal traits of project managers as significant success factors. Muller concluded his paper by stating that his work is merely a first 
step from leadership towards personality theory of project success, and studies on project manager personal traits and project success needs to be expanded.

These researchers are showing that project managers in modern organisations are being challenged like never before, in a personal sense, and require additional competencies to the more traditional ones. They are implementing the strategic intentions in companies that are extremely dynamic, fast-paced and ever-changing, and the expectations on project managers have changed. The latter researchers allude to competencies required that are more intrinsic to the project manager him or herself - whereas previous focus areas were on technical knowledge and methodology (relating to the project itself) and politics or leadership (relating to dealing with others). The following table summarises this evolution.

The researcher will now introduce a concept, or competency, that can significantly equip the Project Manager, or enhance, personal attributes needed for thriving in the modern organisation. The researcher will show that this concept, called self-efficacy, is necessary for the modern project manager to consider and could well provide input into the next level of evolution of the project manager where focus needs to be placed on the intrinsic thoughts and attitudes of the project manager him or herself.

\subsection{Introducing Self-efficacy}

Various modern-day self-efficacy researchers like Ugwu, Onyishi and Tyoyima (2013) still regularly refer to the researcher who pioneered the concept of self-efficacy, Albert Bandura, and his self-efficacy definitions. The term 'self-efficacy' is defined by these researchers as a person's own judgment of their capabilities to organise and execute the courses of action required to attain predetermined goals hence the relevance to project managers. It is not concerned with the skills one has, but rather with the estimation of what one can attain with the skills one possesses. Further to this, these researchers explain self-efficacy as the beliefs in one's capabilities to activate the motivation, cognitive resources, and courses of action needed to meet given situational demands. By definition alone, the study of self-efficacy already appears to be relevant to project management practise. Where previous research focusses on knowledge or application of product, industry or project methodology, and knowledge and application of leadership and people-skills when relating to others, self-efficacy talks to how the project manager relates to him or herself in given projects or situations.

Table 1. The evolution of Project Management effectiveness factors through the years (Approximate)

\begin{tabular}{|l|l|l|}
\hline $\begin{array}{l}\text { Project Management Era } \\
\text { (approximate) }\end{array}$ & Project Management Effectiveness Factor - main focus area & Examples of Researchers \\
\hline $1995-1997$ & $\begin{array}{l}\text { Industry competence eg Civil Engineers or Architects becoming } \\
\text { project managers for construction projects. }\end{array}$ & Pinto and Kharbanda (1995) \\
\hline $1997-2001$ & $\begin{array}{l}\text { Knowledge and implementation of Project Management } \\
\text { lifecycle and methodologies. }\end{array}$ & $\begin{array}{l}\text { Fisk (1997), Themistocleous } \\
\text { and Wearne (2000) }\end{array}$ \\
\hline $2002-2008$ & Leadership ability. & $\begin{array}{l}\text { Turner and Muller (2005), } \\
\text { Neuhauser (2007), } \\
\text { Geoghegan and Dulewicz } \\
\text { (2008) }\end{array}$ \\
\hline $2009-2013$ & $\begin{array}{l}\text { Personal attributes of the Project Manager (PM) eg } \\
\text { physchological profile matching of PM to a project, emotional } \\
\text { competence of the PM, ability of the PM to deal with failure } \\
\text { and stress, personal traits and personality focus. }\end{array}$ & $\begin{array}{l}\text { Muller (2009), Meredith and } \\
\text { Mantel (2010) }\end{array}$ \\
\hline
\end{tabular}

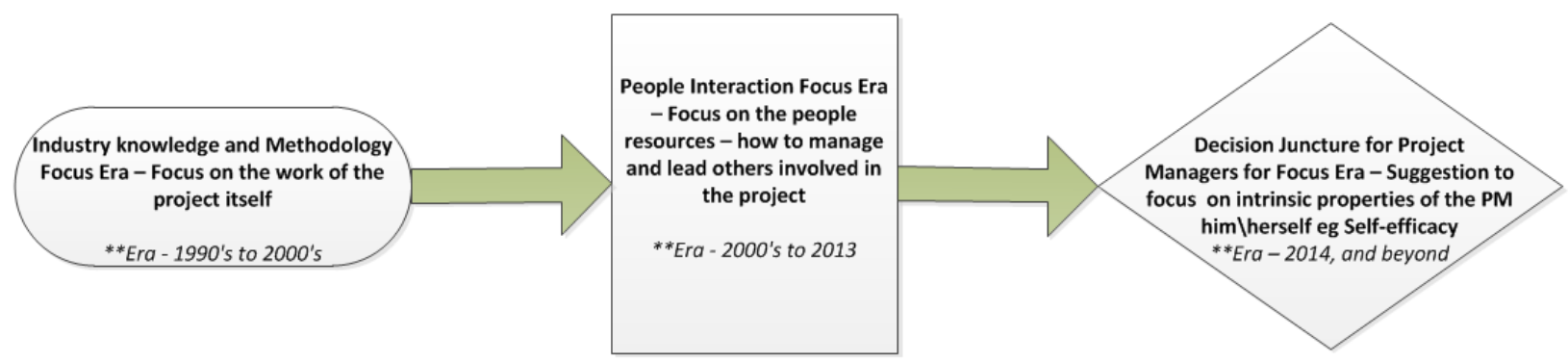

** The researcher suggests that all competency focus areas are still required, but should never be considered all encompassing, as environmental conditions of industry keeps changing, hence project practice and competencies must continue to evolve (eg post-recession attitudes).

Figure 1. Process flow chart of project manager competency emphasis areas and the next area for focus 
Kihlstrom and Harackiewicz (1990), in their review of Bandura's work, stated that efficacy expectations are self-judgements of how well someone can execute courses of action required to deal with prospective situations. Hence, efficacy expectations are future oriented, rather than retrospective, and they are specific to a particular situation and action. The same researchers believed that self-efficacy should be seen as a property of a person, but is not a personality trait. Hence a person can be high on self-efficacy in one domain but low in another, and self-efficacy can be developed in a domain regardless of the personality of an individual. Locke (2009) highlighted self-efficacy's merits in stating that human behaviour is significantly motivated and controlled through self-influence, and that self-efficacy is a significant mechanism for self-influence.

Self-efficacy impacts have been studied in an array of fields and practices, as will be shown in the next section.

\subsection{Effects of Self-efficacy, Self-efficacy Improvement and Relevance to Project Management}

Miles and Maurer (2010) stated that self-efficacy predicts performance and motivation across a wide variety of tasks in corporate environments. The more confidence one has in one's ability to perform a particular task, the more the likelihood that one will participate in the activity, set higher goals than normal, persist through difficulties and ultimately be successful. Locke (2009:180) stated that "efficacy beliefs affect self-motivation and action through their impact on goals and aspirations. It is partly on the basis of efficacy beliefs that people choose what goal challenges to undertake, how much effort to invest in the endeavour, and how long to persevere in the face of difficulties. When faced with obstacles, setbacks and failures, those who doubt their capabilities slacken their efforts, give up prematurely, or settle for poorer solutions. Those who have a strong belief in their capabilities redouble their effort to master the challenges".

Bandura (1997) pointed out that because individuals have the capability to alter their own thinking, self-efficacy beliefs tend to influence physiological states including anxiety, stress and fatigue. Mulki, Lassk and Jaramillo (2008) stated that people who are high in self-efficacy believe in their ability to handle their work well and are more likely to become successful in their careers. Self-efficacy enhances employees' willingness to invest additional effort and master a challenge, and thus plays a significant role in increasing work effectiveness, job satisfaction, and productivity. The work of Breso, Schaufeli and Salanova (2010) on self-efficacy impacts on university students showed that the students with higher self-efficacy than their peers appear to generate and test alternative courses of action when they do not initially achieve success in their studies. They tend to generally cope better with stress and are less likely to suffer burnout. Additionally, the same study showed higher levels of engagement (a positive, fulfilling, and motivational state of mind related to students' tasks that is characterised by vigour, dedication and absorption) amongst students with higher self-efficacy. Chowdhury and Lanis (1999) showed that the factors for the development of self-efficacy are mastery experiences, modelling, social persuasion, and judgments of own physiological states.

Chowdhury and Lanis (1999) further define these factors. Mastery experiences refer to repeated cases of success in a particular task that enhances efficacy, while negative experiences are likely to have the opposite effect. Modelling refers to people judging their efficacy on a task based on the abilities of others similar to themselves completing a similar task through sustained effort. Social persuasion refers to realistic, credible encouragement being given. Lastly, people's judgement of their own psychological states has an impact on their self-efficacy. For instance, sweaty palms before making a speech is not necessarily an indication of being a poor public speaker; or a little anxiety before a big exam is normal for most students, and should not be misinterpreted as an indication of being unprepared for the exam.

The work of researchers on self-efficacy impacts on these areas has clearly made a difference in these fields, from the evidence shown. Self-efficacy effects on the delivery capability of project managers though, have not been formally studied up to now. The researcher endeavours further in this paper, to raise awareness of the likely effects of self-efficacy on project managers in contemporary business environments.

\section{Research Methodology}

In the Literature Review, the researcher displayed a substantial amount of previous research on the effects of self-efficacy on various fields and industries. The researcher envisages that many of the self-efficacy effects already found in previous research on other industries or sectors may apply to project managers, so extensive field research starting from scratch may not be necessary. Hence, the researcher chose a methodology that can utilise the work of these previous researchers on self-efficacy, while creating new knowledge for project practise.

Self-efficacy and its effects however, are not being researched in isolation and it is not the sole intention of this paper to do a mere literature review on the general effects of self-efficacy across all fields. The paper aims to determine the effects of self-efficacy particularly on project managers, and specifically under the pressure of modern organisations. Hence the paper aims to synthesise the research up to now on 3 separate concepts - self-efficacy effects, competencies that make project managers effective and competencies needed in the modern, post-recession dynamic organisation. To achieve this consolidation of research work on these 3 separate concepts, the researcher uses a meta-synthesis research method called meta-ethnography.

As shown in the following research work, meta-ethnography can be seen as a more in-depth form of literature review, as it synthesises into one another, and then translates, separate qualitative studies to form new findings. 
A straightforward literature review, by its nature, simply presents the literature in a raw format on a single concept, either reaching a pervasive conclusion on a topic or critically understanding the gaps in research on the topic. According to Campbell, Pound, Morgan, Daker-White, Britten, Pill, Yardley, Pope and Donovan (2011), the goal of synthesis is to go beyond a normal, narrative literature review, and should involve some degree of conceptual innovation. This is relevant for this current study, as the researcher needed to take results or concepts from different fields that were not previously studied together, like project management, self-efficacy and contemporary organisation effectiveness factors, and synthesise them to show if self-efficacy could make project managers more effective in contemporary companies. Gewurtz and Kirsh (2009) stated that meta-synthesis is a general approach to synthesizing findings across qualitative studies on a particular topic or subject, using methods consistent with qualitative research. Meta-ethnography is a form of meta-synthesis. They state that the idea of meta-synthesis is to produce findings that offer new insights and deeper conceptualizations than can be achieved through separate investigations. They further mention that these high-level concepts are designed to cross contextual boundaries and capture findings from multiple qualitative studies.

Hence, the researcher used a condensed and simplified, "light" meta-ethnography to synthesise the qualitative findings in academia of the 3 separate concepts of self-efficacy effects, the competencies that make project managers effective and personal competencies required to thrive in the modern organisation. A formal academic filtering tool called the Critical Appraisal Skills Programme (CASP), as well as using traditional academic writing principles, was used to ensure that only existing qualitative research of proper academic standard was used in the meta-ethnography.

The researcher then conducted his own qualitative research via e-interviews, on a sample of 12 project managers from diverse industry backgrounds and levels of experience, to determine if the results of the meta-ethnography can be verified by actual project managers in the real world. In so doing, the researcher will show the effect of self-efficacy on project managers in modern organisations, using 2 separate, tried and tested methodologies.

\section{Data Analysis and Interpretation of the Research Findings}

The meta-ethnography commenced with finding any academic work of previous researchers on the three individual concepts of self-efficacy effects, project manager personal effectiveness factors as well as contemporary organisation personal competencies required. This initial "raw data" was extracted between September 2013 and November 2013. The academic sources consulted were EBSCO, the Directory of Open Access Journals (DOAJ), AcademicJournals.org and Google Scholar.

Even though the focus of meta-ethnographic studies is on the synthesis of qualitative studies, the researcher included studies that used quantitative and qualitative data if a subset of the research used or included elements of, but was not limited to, quantitative data. The researcher also used his own discretion while reading through the articles to ensure as much relevance as possible to the aims and context of the research topic. Research that was too far removed from the context of this current research was excluded. The researcher then used the CASP tool to filter articles, to ensure the quality of the studies "fed" into the meta-ethnography process.

This filtering process led the researcher to the reading of titles and abstracts of altogether 75 articles in academia on the topics of self-efficacy effects, project manager effectiveness competencies and competencies required of contemporary leaders and employees. Thirty worthwhile articles from these were read in full, but eventually four articles on self-efficacy effects, one credible source on personal competencies needed for project managers and two articles on contemporary organisation competencies and characteristics were chosen for the meta-ethnography. Quality and relevance to the research topic was imperative.

From this "pool" of previous research, 36 self-efficacy effects were found. 32 contemporary organisation competencies required were collected along with 28 project manager personal competencies needed. The synthesis then led to searching, amongst these, for only competencies and effects that were commonly found amongst the 3 concepts of self-efficacy effects, personal competencies needed for project managers and contemporary organisation competencies required.

This meta-synthesis eventually lead to 5 competencies that were found common to all the combined studies of the 3 concepts. These competencies, along with the researchers referenced in the meta-ethnography, is summarised in Table 2 below. These are Adaptabilitylflexibility, Ability to handle ambiguity, Persistencelperseverance, Emotional Intelligence and Resilience. Hence the meta-ethnography portion of the research showed that self-efficacy effects project managers in contemporary organisations particularly improving their competencies in these areas. Considering the definitions of these competencies, explained below, it appears evident how these are sorely needed for project management in modern business environments. 
Table 2. Meta-ethnography results of competencies or attributes found to be effects of self-efficacy that make project managers more effective in contemporary environments

\begin{tabular}{|l|l|l|l|l|l|l|l|}
\hline $\begin{array}{l}\text { Attributes/Competencies } \\
\text { found }\end{array}$ & $\begin{array}{l}\text { Self-efficacy } \\
\text { Effects Researcher } \\
1\end{array}$ & $\begin{array}{l}\text { Self-efficacy } \\
\text { Effects Researcher } \\
2\end{array}$ & $\begin{array}{l}\text { Self-efficacy Effects } \\
\text { Researcher 3 }\end{array}$ & $\begin{array}{l}\text { Self-efficacy } \\
\text { Effects } \\
\text { Researcher 4 }\end{array}$ & $\begin{array}{l}\text { Contemporary } \\
\text { Competencies } \\
\text { Researcher 1 }\end{array}$ & $\begin{array}{l}\text { Contemporary Competencies } \\
\text { Researcher 2 }\end{array}$ & $\begin{array}{l}\text { PM Personal } \\
\text { Competencies } \\
\text { Researcher }\end{array}$ \\
\hline Emotional Intelligence (EO) & Breso et al. (2010) & & & & Swarnalatha \& Prasanna (2012) & PMI (2007) \\
\hline Adaptability/Flexibility & Mulki et al. (2008) & & & & Salas-Pilco (2013) & & PMI (2007) \\
\hline Ability to handle ambiguity & Mulki et al. (2008) & & & & Salas-Pilco (2013) & & PMI (2007) \\
\hline PersistencelPerseverance & Mulki et al. (2008) & Breso et al. (2010) & Miles \& Maurer (2012) & Locke (2009) & & & PMI (2007) \\
\hline Resilience & & Breso et al. (2010) & & Locke (2009) & & Swarnalatha \& Prasanna (2012) & PMI (2007) \\
\hline
\end{tabular}

The Iowa Core education organisation (2011) defines "Adaptabilitylflexibility" as being capable to adapt to new, different or changing requirements. It further states that "Twenty-first century flexibility and adaptability" reflects engagement in innovation and creativity, intellectual agility and embracing change. It adds, purposeful and thoughtful response to disruptions, acknowledging and responding to dissonance in productive ways as well as proactive and reactive approaches to change, as part and parcel of "Adaptabilitylflexibility".

Collins Dictionary (2017) explains "ambiguity" well for the context of project management in modern environments, as something that is unclear, confusing or can be interpreted in more than one way. Additionally, it states that ambiguity in a situation means that it contains several different qualities or attitudes which do not fit well together. This definition further accentuates the "Ability to handle ambiguity" competency.

"Persistencelperseverance", which is closely related to the term "grit", is defined by Duckworth, Peterson, Matthews and Kelly (2007) as "perseverance and passion for long-term goals". Furthermore, it is defined by the same researchers as working strenuously toward challenges, maintaining effort and interest over an extended period, despite failure, adversity, and plateaus.

The pioneers of the term "Emotional Intelligence", Salovey and Mayer (1990), define the term as "the ability to monitor one's own and others feelings and emotions, to discriminate among them, and to use this information to guide one's thinking and actions".

Oxforddictionaries.com defines "resilience" as "the capacity to recover quickly from difficulties; toughness" and "the ability of a substance or object to spring back into shape".

Considering the definitions of these competencies along with the research results of this paper, it becomes clear how these are needed by contemporary project managers.

Following the meta-ethnography, e-interviews, a modern form of qualitative questioning using various forms of digital technology, were then used for verification of the meta-ethnography results. The e-interviews were distributed via e-mail to a sample of 12 diverse, actual project managers working in an enterprise project office in a modern, dynamic organisation.

The interview protocol consisted of an explanation of the background to the research, the hypothesis, as well as the results from the meta-ethnography seen above. Self-efficacy was also explained in detail. The project managers were questioned on the relevance of each of the 5 competencies discovered in the meta-ethnography, to their perceived effectiveness in their role, in open and closed-style questioning. There were 5 questions asked in the e-interview, 1 per competency found in the meta-ethnography (results found, above).

Some very eye-opening responses were received by the researcher, providing insight over and above what was envisaged. Overall, for the specific purposes of the research objectives, $80 \%$ of the respondents agreed with Adaptability|Flexibility, $100 \%$ agreed with Ability to handle ambiguity, $80 \%$ agreed with Persistence $\backslash$ Perseverance, $60 \%$ with Resilience and $60 \%$ with Emotional Intelligence impacts of self-efficacy.

Hence, the researcher is satisfied that a majority of the e-interview respondents agreed that self-efficacy resulted in, or affected, these 5 competencies or attributes in their project management role in their contemporary organisation. In so doing, this shows, via the meta-ethnography combined with qualitative questioning, the effect of self-efficacy improvement on the effectiveness of project managers in contemporary organisations. Figure 2 below, summarises the holistic research process used by the researcher. 


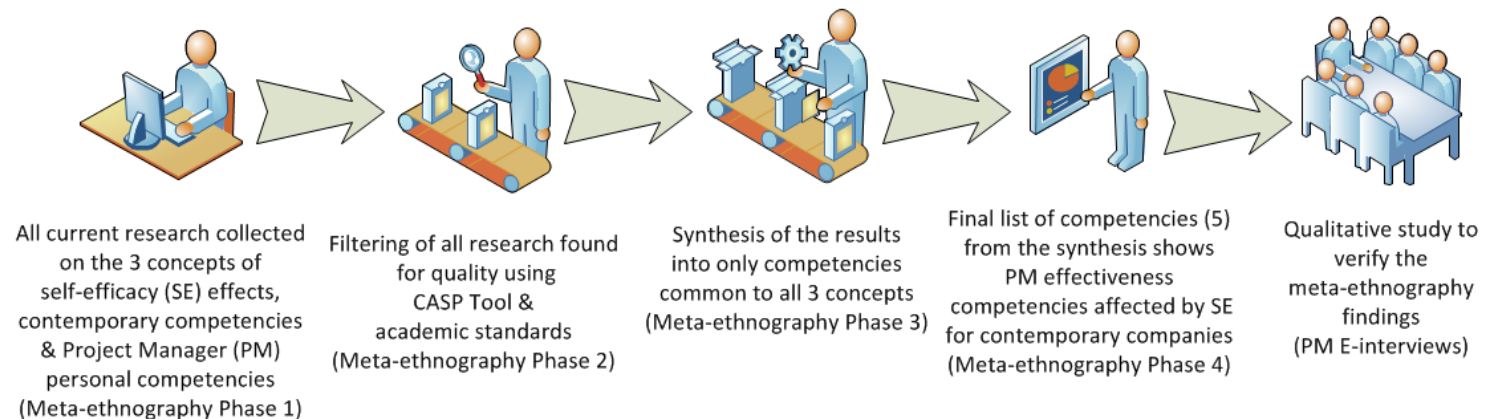

Figure 2. A summary of the research process that yielded the results

\section{Conclusions}

Due to changes in environmental factors in companies, competencies required of project managers will need to continually evolve. Mere technical or industry skill, project methodology application and leadership ability has largely been the focus of project management competencies required up to now, but will not suffice for the modern-day project manager. Project managers today typically operate in corporate environments that are increasingly stressful, hostile and cut-throat. Recent factors like the global recession, modern technology and the Internet have changed the outlook of the modern organisation and its expectations.

Project managers now require deeper, intrinsic and more personal qualities than what has been focussed on through the years, to thrive in their role. Previous areas of focus were on industry or technical knowledge and project methodology (management of the work of the project itself) as well as leadership and interpersonal skills (management of other people involved in the project). The next generation of project manager must consider focus on him or herself and his or her self-efficacy for increased effectiveness; where self-efficacy is a person's own judgment of their capabilities to organise and execute the courses of action required to attain predetermined goals. The paper has shown self-efficacy to have a positive effect on the following personal, intrinsic attributes sorely needed in the modern organisation - Adaptabilitylflexibility, Ability to handle ambiguity, Persistencelperseverance, Emotional Intelligence and Resilience.

Hence, the ability of a project manager to understand self-efficacy, the impact it has on project management effectiveness and how to nurture and maintain it in any particular project or situation, will make the project manager more effective in contemporary organisations.

\section{REFERENCES}

[1] Arain, F.M. and Tipu, S.A. 2009. 'Status of project management education in Pakistan', Educational Research and Review, 4(4), 148-155.
[2] Bandura, A. 1997. Self-efficacy: The exercise of control. New York, NY: Freeman \& Co.

[3] Binde, J. and Saulite, I. 2013. 'The role of leadership in project-oriented organizations' in PAPM, (Professional Association of Project Managers) 2nd International scientific conference on Project Management in the Baltic countries. Riga, Latvia, 11-12 April 2013.

[4] Breso, E., Schaufeli, W.B. and Salanova, M. 2010. 'Can a self-efficacy-based intervention decrease burnout, increase engagement, and enhance performance? A quasi-experimental study', Available from: http://link.springer.com/article/10.1007/s10734-010-9334-6/f ulltext.html (accessed 04 November 2013).

[5] Campbell, R., Pound, P., Morgan, M., Daker-White G., Britten, N., Pill, R., Yardley, L., Pope, C., Donovan, J. 2011, 'Evaluating meta-ethnography: systematic analysis and synthesis of qualitative research', Health Technology Assessment, 15(43).

[6] Chowdry, S. and Lanis, T. 1999. 'Importance of self-efficacy of working in team environments in determining individual satisfaction and performance: Does it depend on the team performance?', Available from:

https://wikispaces.psu.edu/download/attachments/67017379/ 08.pdf (accessed 01 July 2014).

[7] Coetzee, R., Visagie, J. and Ukpere, W. 2012. 'Leading a successful change intervention in a modern organisation: Key elements to consider', African Journal of Business Management, 51(6), 12068-12075.

[8] Collins Dictionary. 2017. 'Definition of 'ambiguity', Available from:

https://www.collinsdictionary.com/dictionary/english/ambig uity (accessed 20 March 2017).

[9] Duckworth, A.L., Peterson, C., Matthews, M.D. and Kelly, D.R. 2007. 'Grit: Perseverance and Passion for Long-Term Goals', Journal of Personality and Social Psychology, 92(6), 1087-1101.

[10] Fisk, E.R. 1997. Construction Project Administration. (5th ed.). Hoboken, N.J.: John Wiley \& Sons, Inc.

[11] Geoghegan, L. and Dulewicz, V. 2008. 'Do Project Managers' leadership competencies contribute to project success?', Project Management Journal, 39(4), 58-67.

[12] Gewurtz, R. and Kirsh, B. 2009. 'Disruption, disbelief and resistance: A meta-synthesis of disability in the workplace', Work: A Journal of Prevention, Assessment and Rehabilitation, 34(1), 33-44. 
[13] Gul, S. 2011. 'An overview and critical review on developments in the last thirty years within project management', African Journal of Business Management, 35(5), 13566-13579.

[14] Iowa Core. 2011. 'Flexibility and Adaptability', Available from:

https://sites.google.com/a/aea11.k12.ia.us/heartlandweb2curr iculum/flexability-and-adaptability (accessed 20 March 2017).

[15] Kihlstrom, J. F. and Harackiewicz, J. M. 1990. 'An evolutionary milestone in the psychology of personality'. Psychological inquiry, 1(1), 86-92.

[16] Locke, E.A. 2009. Handbook of principles of Organisational Behaviour - indispensable knowledge for evidence-based management. (2nd ed.). West Sussex, UK: John Wiley \& Sons, Inc.

[17] Meredith, J.R. and Mantel, S.J. 2010. Project Management: A managerial approach. (7th ed.). Hoboken, N.J.: John Wiley $\&$ Sons, Inc.

[18] Miles, E.W. and Maurer, T.J. 2012. 'Advancing validity of self-efficacy in negotiation through focusing at the domain level', Journal of Occupational and Organizational Psychology, 85(1), 23-41.

[19] Mulki, J.P., Lassk, F.G. and Jaramillo, F. 2008. 'The effect of self-efficacy on salesperson work overload and pay satisfaction', Journal of Personal Selling and Sales Management, 153(3), 285-297.

[20] Muller, R. 2009. 'Attitudes and leadership competencies for project success' in Insights into the Sustainable Growth of Business Conference 2009. 19-21 November 2009, Vilnius: Lithuania.
[21] Neuhauser, C. 2007. 'Project Manager leadership behaviours and frequency of use by female Project Managers', Project Management Journal, 38(1), 21-31.

[22] Oxford Dictionary. 2017. 'Resilience', Available from: https://en.oxforddictionaries.com/definition/resilience (accessed 23 March 2017).

[23] Pinto, J.K. and Kharbanda, O.P. 1995 'Lessons for an accidental profession', Business Horizons, 38(2), 41-51.

[24] Project Management Institute (PMI). 2007. Project Manager Competency Development Framework (2nd ed.). Project Management Institute, Pennsylvania.

[25] Salas-Pilco, S.Z. 2013, 'Evolution of the framework for 21st century competencies', Knowledge Management \& E-Learning, 5(1), 10-24.

[26] Salovey, P. and Mayer, J.D. 1990. Emotional Intelligence. New York, NY: Baywood Publishing Co., Inc.

[27] Swarnalatha, C. and Prasanna, T.S. 2012. 'Positive Organisational Behaviour: engaged employees in flourishing organisations', International Journal of Management Research and Development, 2(1), 18-26.

[28] Themistocleous, G. and Wearne, S.H. 2000. 'Project Management topic coverage in journals', International Journal of Project Management, 18(1), 7-11.

[29] Turner, R.J. and Müller, R. 2005. 'The Project Manager's role as a success factor on projects: a literature review', Project Management Journal, 36(2), 49-61.

[30] Ugwu, F.O., Onyishi, I.E. and Tyoyima, W.A. 2013. 'Exploring the relationships between academic burnout, self-efficacy and academic engagement among Nigerian college students", The African Symposium, 13(2), 38-45. 